\title{
ANALISIS POTENSI PERIKANAN PELAGIS KECIL DI KOTA TERNATE
}

\author{
Aisyah Bafagih* \\ *Staf Pengajar THP UMMU-Ternate, email :aisyahbafagih2@yahoo.com
}

\begin{abstract}
ABSTRAK
Potensi sumberdaya perikanan tangkap di kota ternate merupakan komoditi unggulan bagi masyarakat nelayan, karena komoditi ini memiliki mekanisme pemasaran langsung, efekif dan efisien ke wilayah sekitarnya, yang tentunya memberikan keuntungan yang cukup besar. Hal ini akan memberikan manfaat sosial dan ekonomi kepada masyarakat secara keseluruhan, dan yang lebih penting untuk masyarakat nelayan sehingga tercapainya keadilan (equity), pertumbuhan (growth) dan keberlanjutan (sustainability.)Tujuan penelitian untuk mengkaji tingkat potensi sumberdaya perikanan tangkap, khususnya ikan pelagis kecil di kota Ternate yang dihubungkan dengan faktor-faktor teknis untuk mengetahui potensi lestari. Alat tangkap yang digunakan mempunyai pengaruh terhadap dampak dari potensi yang dimiliki dan faktor pendukung terhadap hasil produksi yang dicapai. Nilai MSY yang diperoleh dari analisis dengan model Schaefer terhadap upaya tangkap (effort) dan hasil tangkapan (catch) menunjukan penagngkapan lestari sebesar 10.999.564 ton/tahun dengan upaya penangkapan sebesar 11.150,173 unit alat tangkap. Faktor teknis produksi dari perhitungan regresi untuk alat tangkap Pole and Line (huhate) dan Purse Seine (pajeko) menunjukan hasil tangkapan sangat berpengaruh terhadap jumlah tenaga kerja, hari operasi penangkapan, jumlah bahan bakar serta kapasitas ukuran kapal.
\end{abstract}

Kata kunci: Ternate, ikan pelagis, huhate, pajeko.

\section{PENDAHULUAN}

\subsection{Latar Belakang}

Indonesia merupakan negara kepulauan terbesar di dunia dengan wilayah daratatan 1,9 juta $\mathbf{k m}^{2}$, wilayah laut sekitar 5,8 juta $\mathbf{k m}^{2}$, jumlah pulau 17.508 buah dengan panjang garis pantai terpanjang kedua di dunia setelah Kanada yaitu 81.000 km. Dengan kondisi ini membuat Indonesia memiliki potensi sumberdaya perikanan laut yang sangat besar.

Sumberdaya perikanan pelagis merupakan salah satu bagian terpenting dari potensi sumberdaya perikanan laut di Indonesia dan merupakan bahan konsumsi dalam negeri. Sumberdaya perikanan laut tersebut perlu dijaga kelestariannya agar dapat dimanfaatkan secara terus menerus dan dapat juga dinikmati oleh generasi yang akan datang. Salah satu pertanyaan mendasar dalam pengelolaan sumberdaya ikan adalah bagaimana memanfaatkan sumberdaya tersebut sehingga menghasilkan manfaat ekonomi yang tinggi bagi pengguna, namun kelestariannya tetap terjaga.

Besarnya potensi sumberdaya perikanan mempunyai peranan penting dalam pembangunan sosial dan ekonomi wilayah. Hal ini memberikan manfaat sosial dan ekonomi kepada masyarakat secara keseluruhan, terutama bagi masyarakat nelayan, dalam rangka mewujudkan keseimbangan antara keadilan (equity), pertumbuhan (growth) dan keberlanjutan (sustainability).

Komoditi perikanan laut khususnya perikanan tangkap merupakan komoditi unggulan bagi masyarakat nelayan khususnya di Kota Ternate, karena komoditi ini memiliki mekanisme pemasaran langsung, efektif dan efisien ke wilayah sekitarnya, yang tentunya memberikan keuntungan yang cukup besar.

Untuk memperoleh keuntungan dengan memperhatikan kelestarian sumberdaya 


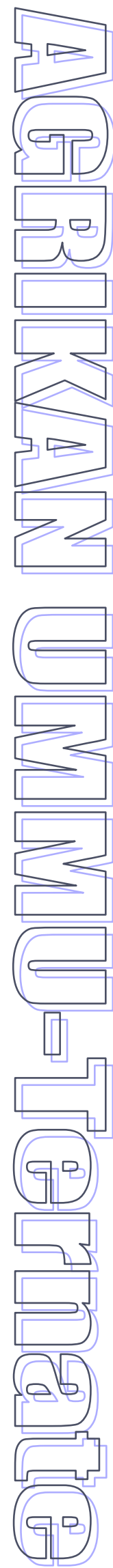

perikanan pelagis di Kota Ternate, maka perlu dilakukan suatu usaha pendekatan yang memperhatikan aspek biologis dan ekonomis, sehingga nelayan dalam melakukan aktifitasnya dapat memperoleh keuntungan secara maksimal tetapi sumberdaya ikan tetap lestari. Clark (1985) in Purwanto (2002), mengungkapkan bahwa pendekatan bioekonomi adalah pendekatan yang memadukan kekuatan ekonomi yang mempengaruhi industri penangkapan dan faktor biologi yang menentukan produksi suplai ikan. Untuk itu maka digunakan pendekatan bioekonomi untuk mengestimasi aspek biologi, dan ekonomi dalam melakukan usaha penangkapan ikan.

\subsection{Tujuan Penelitian}

Penelitian ini untuk mengestimasi Maximum Sustainable Yield (MSY) sumberdaya perikanan pelagis kecil serta mengestimasi Effort Maximum Sustainable Yield (EмsY), di Kota Ternate, serta menentukan hubungan antara potensi sumberdaya dengan faktorfaktor produksi yang berperan dalam pengoperasian alat tangkap pada perikanan pelagis kecil.

\subsection{Manfaat Penelitian}

Sebagai masukan bagi instansi terkait untuk menjadi pertimbangan pengambilan kebijakan dalam mengupayakan manajemen pengelolaan sumberdaya perikanan tangkap dan menjaga kelestarian sumberdaya ikan dengan mempertimbangkan faktor biologisnya.

\section{METODE PENELITIAN}

\subsection{Waktu, Lokasi dan Alur Penelitian}

Penelitian ini mengambil lokasi di Kota Ternate yang ditentukan secara purposive sampling, dengan pertimbangan sebagai berikut: lokasi yang dipilih merupakan desa pantai dimana secara kultur sebagian masyarakatnya merupakan masyarakat nelayan, selain tingginya aktifitas pemanfatan sumberdaya wilayah pesisir di wilayah tersebut. Desa yang terpilih dalam penelitian sebanyak 8 desa (berada pada 4 pulau di 3 kecamatan) yaitu Lilewi (pulau Batang Dua), Loto, Rua, dan Dufa-Dufa (pulau Ternate),
Dorari Isa dan Togolobe (pulau Hiri) serta Moti Kota dan Tafamutu (pulau Moti), yang dilakukan pada bulan Agustus 2014 - bulan Pebruari 2015. Di samping data pengamatan langsung di lapangan juga diambil data yang bersifat sekunder dari berbagai instansi terkait yang berhubungan dengan penelitian ini, untuk kurun waktu 2006 - 2013.

\subsection{Analisis Data}

Parameter biologi berupa data time series ditabulasi untuk mengestimasi MSY dan EMSY dengan menggunakan metode Schaefer (1954). Kemudian data primer yang terkumpul berdasarkan wawancara dan turun lapang langsung dianalisis dengan metode analisis faktor produksi menggunakan regresi linear berganda.

Analisis data yang dilakukan pada penelitian ini didasarkan pada batasan:

1) Potensi sumberdaya ikan yang terdapat didaerah penelitian dihitung berdasarkan hasil tangkapan kapal yang menangkap jenis hasil tangkapan dari unit alat tangkap.

2) Kapal-kapal yang diteliti adalah kapal yang fishing base di Pulau Ternate dan beroperasi di perairan wilayah $\mathrm{Kab} / K o t a$ Ternate.

\subsubsection{Standarisasi Alat Tangkap}

Standarisasi dilakukan karena alat tangkap yang digunakan oleh nelayan untuk menangkap target sumberdaya perikanan begitu beragam, sehingga sangat dimungkinkan satu spesies ikan tertangkap oleh dua alat tangkap yang berbeda atau lebih. Alat tangkap yang dijadikan standart adalah alat tangkap yang memiliki produktivitas tinggi (dominan) dalam menangkap sumberdaya perikanan yang menjadi objek penelitian atau memiliki rata-rata CPUE terbesar pada suatu periode waktu dan memiliki nilai faktor daya tangkap sama dengan satu.

\subsubsection{Analisis Fungsi Produksi}

Analisis fungsi produksi yang sering dilakukan oleh peneliti untuk memperoleh informasi hubungan antara faktor produksi dapat digunakan dengan fungsi linear atau fungsi kuadratik. Umumnya yang sering dipakai adalah fungsi linear dengan analisis regresi (Stell and Torrie 1989). Peubah Y 


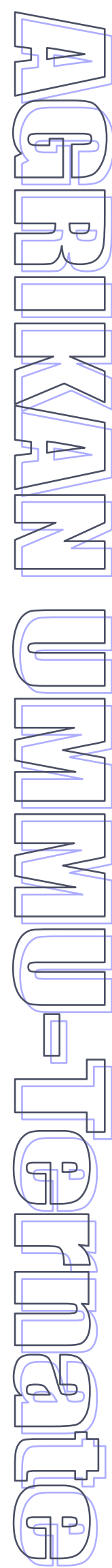

disebut sebagai peubah tidak bebas, sedangkan peubah $X$ disebut peubah bebas. Apabila lebih dari satu peubah maka disebut dengan garis regresi linear berganda. Hubungan antara faktor-faktor produksi dengan produksi unit penangkapan dari beberapa alat tangkap dalam penelitian ini akan dianalisis menggunakan persamaan regresi linear berganda (Stell and Torrie,1981) dengan satuan analisisnya adalah unit kapal/ trip. Persamaannya sebagai berikut:

$$
Y=b_{o}+b_{1} X_{1}+b_{2} X_{2}+b_{3} X_{3}+\cdots .+b_{n} X_{n}+e
$$

keterangan:

$\mathbf{Y}=$ nilai dugaan produksi atau nilai variabel tak bebas

$B_{0}=$ peubah pengganggu (intercept)

$B_{1}=$ koefisien regresi

$\mathrm{X}_{1}=$ koefisien produksi yang digunakan

n $=$ jumlah variabel

e = galat/kesalahan

Variabel-variabel yang ditentukan dan diukur dilapangan adalah:

1. Variabel tak bebas: Hasil tangkapan (Y)

Hasil tangkapan yang dimaksud adalah jumlah hasil tangkapan yang diperoleh dalam satu kali usaha penangkapan. Satuan ukuran yang digunakan dalam hasil tangkapan adalah $\mathrm{kg} /$ trip

2. Variabel bebas (X)

Variabel bebas yang digunakan sebagai faktor-faktor teknis produksi dalam penangkapan beberapa alat tangkap dominan antara lain tenaga kerja (ABK), jumlah bahan bakar, panjang jaring (purse seine, gilnet), tinggi jaring (purse seine, gilnet), jumlah hari melaut dan ukuran kapal

a. jumlah tenaga kerja (x1/orang)

b. jumlah bahan bakar $\left(X_{2} /\right.$ liter $)$

c. panjang jaring purse seine dan gillnet $\left(\mathrm{X}_{3} /\right.$ meter $)$

d. Tinggi jaring purse seine dan ( $\left.\mathrm{X}_{4} / \mathrm{meter}\right)$

e. Jumlah hari melaut $\left(\mathrm{X}_{5} /\right.$ trip)

f. Ukuran kapal ( $\left.\mathrm{X}_{6} / \mathrm{GT}\right)$

Penggunaan hubungan antara faktorfaktor produksi dengan produksi, diuji dengan pengujian hipotesis yang menggunakan uji statistik. $H_{0} ; b_{1}=0$ (untuk $i=1,2,3 . . . n$ ). ini berarti antara hasil tangkapan ( $Y$ ) dengan faktor teknis produksi $\left(X_{1}\right)$ tidak ada hubungan yang nyata. $H_{1}=b_{1} \neq 0$ (untuk $i=1,2,3, \ldots . . n$ )
Ini berarti bahwa hasil tangkapan (Y) memiliki hubungan yang nyata terhadap faktor teknis produksi (X1)

$$
\begin{aligned}
& \text { Jika }: F_{\text {hitung }}>F_{\text {tabel }} \\
& F_{\text {hitung }}<F_{\text {tabel }} \longrightarrow H_{o} \text { ditolak } \\
& H_{o} \text { diterima }
\end{aligned}
$$

\section{HASIL dan PEMBAHASAN}

\subsection{Produksi penangkapan}

Secara geografis, Ternate merupakan pulau kecil yang dikelilingi oleh lautan, dengan luas wilayah laut yang dimiliki sebesar $903,73 \mathrm{~km}^{2}$. Di dalamnya terdapat berbagai potensi sumberdaya alam yang bernilai ekonomis penting yakni perikanan pantai (coastal), ekosistem terumbu karang, ekosistem mangrove, ekosistem padang lamun dan sumber daya perikanan tangkap yaitu ikan demersial dan pelagis. Ikan pelagis terbagi menjadi pelagis besar dan pelagis kecil, yang dilihat berdasarkan ukuran panjang dan bobot serta habitat dan areal migrasi atau ruaya. Potensi hasil tangkapan di Kota Ternate sangat besar, ditunjukkan dengan tingkat rata-rata produksi ikan hasil tangkapan di Kota Ternate pada tahun 2006-2013 menunjukkan tren peningkatan.

Menurut data BPS Kota Ternate (2006) dan Dinas Perikanan dan Kelautan Provinsi Maluku Utara (2010-20014), pada periode tahun 2004-2013, perkembangan produksi rata-rata tahunan perikanan tangkap di Kota Ternate meningkat sebesar $14,61 \%$. Dalam periode ini juga terlihat terjadinya penurunan produksi yaitu pada tahun 2005 sebesar $4.99 \%$ dan tahun 2007 sebesar 4,60\%. Hai ini diakibatkan terjadinya konflik sosial akibat dari Pilkada yang menguras waktu selama 2 tahun sehingga banyak nelayan yang tidak melaut dikarenakan tersebarnya isu-isu profokatif antara pendukung, sehingga muncul berbagai spekulasi kejadian pada saat itu. Tabel 1 memperlihatkan perkembangan produksi hasil perikanan tangkap Kota Ternate dalam kurun waktu 10 tahun terakhir mulai tahun 2004-2013.

Produksi dari hasil tangkapan kemudian ditabelkan lagi berdasarkan ikan dominan beberapa ikan pelagis seperti cakalang (Katsuwonus pelamis), layang (Decapterus lajang), dan tongkol (Auxis thazard). Keseluruhan jenis ikan yang ditangkap tersebut didominasi oleh cakalang (Katsuwonus 


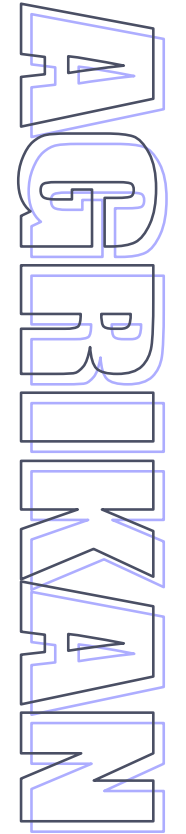

pelamis) dengan volume produksi sebesar

Kelautan dan Perikanan Kota Ternate, 2010). 7.778,3 ton, diikuti kemudian oleh layang (Decapterus spp) sebesar 2.429,3 ton, dan teri Untuk lebih jelasnya dapat dilihat pada Tabel 2 (Stolephorus spp) sebesar 1.750 .50 ton (Dinas berikut.

Tabel 1. Perkembangan produksi hasil perikanan di Kota Ternate 2004-2013

\begin{tabular}{ccc} 
Tahun & $\begin{array}{c}\text { Jumlah Produksi } \\
\text { (Ton) }\end{array}$ & $\begin{array}{c}\text { Perkembangan } \\
(\%)\end{array}$ \\
\hline 2004 & $5.865,34$ & $(15,21)$ \\
2005 & $5.158,31$ & 4,99 \\
2006 & $7.130,00$ & 15,78 \\
2007 & $7.457,84$ & 4,60 \\
2008 & $9.998,50$ & 34,07 \\
2009 & $12.759,06$ & 27,61 \\
2010 & $12.064,26$ & $(5,45)$ \\
2011 & $15.305,52$ & 26,87 \\
2012 & $17.866,21$ & 16,73 \\
2013 & $24.311,41$ & 36,07 \\
\hline
\end{tabular}

Sumber: BPS Kota Ternate (2006); Dinas Perikanan dan Kelautan Provinsi Maluku Utara (2010-2014)

Tabel 2. Perkembangan volume produksi menurut jenis ikan dominan di Kota Ternate, $2005-2012$

\begin{tabular}{crrr}
\hline \multirow{2}{*}{ Tahun } & \multicolumn{2}{c}{ Jenis lkan } \\
\cline { 2 - 4 } & $\begin{array}{c}\text { Cakalang/ } \\
\text { Tongkol }\end{array}$ & Layang & Teri \\
\hline 2005 & $5.717,4$ & $1.611,6$ & $1.523,8$ \\
2006 & $6.073,7$ & $1.621,2$ & $1.548,5$ \\
2007 & $5.811,5$ & $1.639,3$ & $1.569,5$ \\
2008 & $6.213,7$ & $1.781,4$ & $1.577,9$ \\
2009 & $6.784,1$ & $1.833,7$ & $1.608,6$ \\
2010 & $7.434,5$ & $2.216,3$ & $1.638,9$ \\
2011 & $7.477,3$ & $2.252,7$ & 1.739 .2 \\
2012 & $7.778,3$ & $2.429,3$ & $1.750,5$ \\
\hline
\end{tabular}

Sumber: Dinas Kelautan dan Perikanan Kota Ternate (2010)

3.2. Produksi Surplus Stok Sumberdaya Pelagis Kecil

Potensi stok sumberdaya dengan menggunakan model produksi surplus dilakukan untuk mengetahui daya dukung sumberdaya ikan terhadap upaya penangkapan (effort). Model produksi surplus yang akan dikaji berkaitan dengan suatu stok secara keseluruhan, yaitu upaya total dan Potensi stok sumberdaya dengan menggunakan model produksi surplus dilakukan untuk mengetahui daya dukung sumberdaya ikan terhadap upaya penangkapan (effort). Model produksi surplus yang akan dikaji berkaitan dengan suatu stok secara keseluruhan, yaitu upaya total dan hasil penangkapan total yang diperoleh dari stok. Tujuannya adalah untuk menentukan tingkat upaya optimum yang dapat menghasilkan suatu hasil tangkapan optimum sumberdaya tanpa mempengaruhi produktifitas stok jangka panjang, yang dikenal dengan hasil tangkapan maksimum lestari (Maximum Sustainable Yield/MSY) (Sparred and Venema, 1999). Perhitungan MSY didasarkan pada adanya data tahunan tingkat eksploitasi dan upaya penangkapan. Metode yang dilakukan pada perhitungan penelitian ini menggunakan metode Schaefer (1954).

Pada Tabel 3 disajikan hasil tangkapan setelah dilakukan standardisasi terhadap alat tangkap atau upaya penangkapan (effort). Berdasarkan Tabel 3 terlihat bahwa hasil tangkapan pelagis kecil di Kota Ternate berfluktuasi selama kurun waktu 2005-2012. Dari tahun 2005-2006 terjadi peningkatan penangkapan, namun terjadi penurunan hasil tangkapan pada tahun 2006 sebesar 5811.5 ton dan mengalami peningkatan lagi pada tahun 
सत्वें
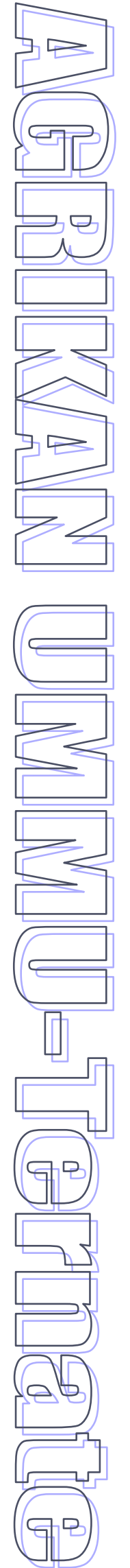

2007 sebesar 158 ton menjadi 6213.7 ton, serta terus menerus menunjukkan peningkatan sampai tahun 2012 sebesar 333,9 ton menjadi 7778.3 ton.

\subsubsection{Model Schaefer}

Mengingat armada perikanan yang digunakan dalam kegiatan penangkapan ikan khususnya pada perikanan pelagis kecil di Kota Ternate terdiri dari beberapa alat tangkap, maka upaya (effort) dari setiap alat tangkap Kota Ternate tahun 2005-2012

Sumber : Dinas Kelautan dan Perikanan Kota Ternate, 2013 2012 tersebut dikonversi menjadi unit standard sebelum penjumlahan untuk memperoleh upaya total (Sparred and Venema, 1999).

Hasil analisis dengan model Schaefer terhadap upaya tangkap (effort) dan hasil tangkapan (catch) menunjukkan hasil penangkapan lestari di Kota Ternate sebesar $10.999,69$ ton per tahun dengan upaya penangkapan optimum sebesar 11,150,43 trip.

Tabel 3. Hasil produksi per unit upaya penangkapan ikan menggunakan alat pole and line di

\begin{tabular}{cccc}
\hline Tahun & $\begin{array}{c}\text { Produksi } \\
\text { (ton) }\end{array}$ & $\begin{array}{c}\text { Effort } \\
\text { (trip) }\end{array}$ & $\begin{array}{c}\text { CPUE } \\
\text { (ton/trip) }\end{array}$ \\
\hline 2005 & 5717.4 & 2723.94 & 2.10 \\
2006 & 6073.7 & 6298.32 & 0.96 \\
2007 & 5811.5 & 17070.49 & 0.34 \\
2008 & 6213.7 & 18582.56 & 0.33 \\
2009 & 6784.1 & 18104.28 & 0.37 \\
2010 & 7434.5 & 17297.42 & 0.43 \\
2011 & 7477.3 & 19021.57 & 0.39 \\
2012 & 7778.3 & 18855.87 & 0.41 \\
\hline
\end{tabular}

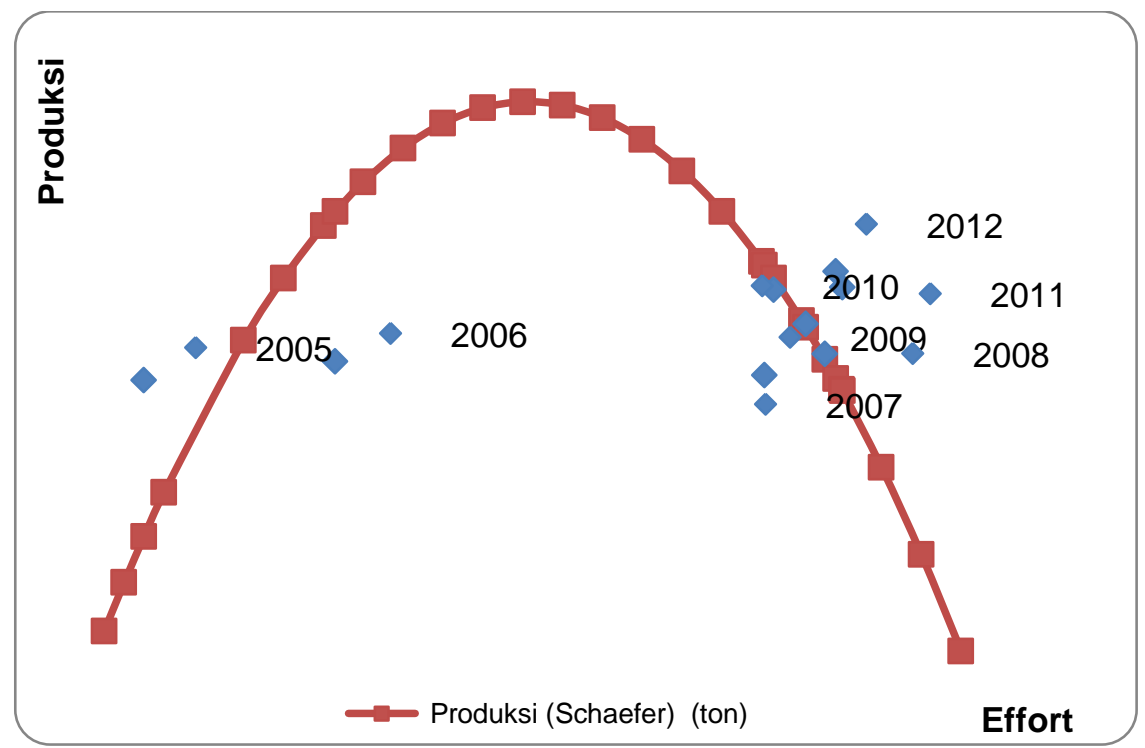

Gambar 1. Pendugaan produksi lestari (MSY) perikana pelagis kecil di Kota Ternate tahun 2005 -

Walaupun terjadi peningkatan secara produksi, namun terlihat telah terjadi overfishing bila dilihat produksi aktual dimana masing-masing sebesar 7477,3 dan 7778,3 ton/tahun telah melebihi produksi lestari (MSY) yang diperbolehkan yaitu 5518,5 dan 5746,8 ton/tahun. Untuk pemanfaatan potensi sumberdaya ikan atas prinsip kehati-hatian maka potensi ikan yang diperbolehkan untuk ditangkap sebesar $80 \%$ yang dikenal dengan TAC (Total Allowable Catch) dari potensi lestari (MSY)

Analisis regresi linear CPUE terhadap upaya penangkapan diperoleh nilai a (intercept) 


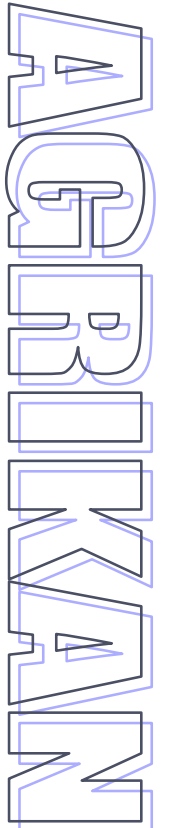

sebesar 1,97296223 dan nilai b (slope) sebesar -

memasukkan nilai upaya maksimum (Eмsч) 0000008847, sehingga persamaan lestari Schaefer adalah

$$
\mathrm{Y}=\mathbf{a} \cdot \mathbf{E}-\mathbf{b} \cdot \mathrm{E}^{2}
$$

tersebut ke dalam persamaan penangkapan lestari didapatkan tingkat produksi lestari $\left(\mathrm{Y}_{\mathrm{MSY}}\right)=55.752,173$ ton. hubungan antara Persamaan Schaefer di atas diperoleh nilai a dan $b$ yang dapat digunakan untuk mengetahui upaya penangkapan maksimum produksi hasil tangkapan terhadap upaya penangkapan (CPUE) dapat dilihat pada Gambar 2. yaitu $($ EмsY $)=10.196,72$ trip. Setelah

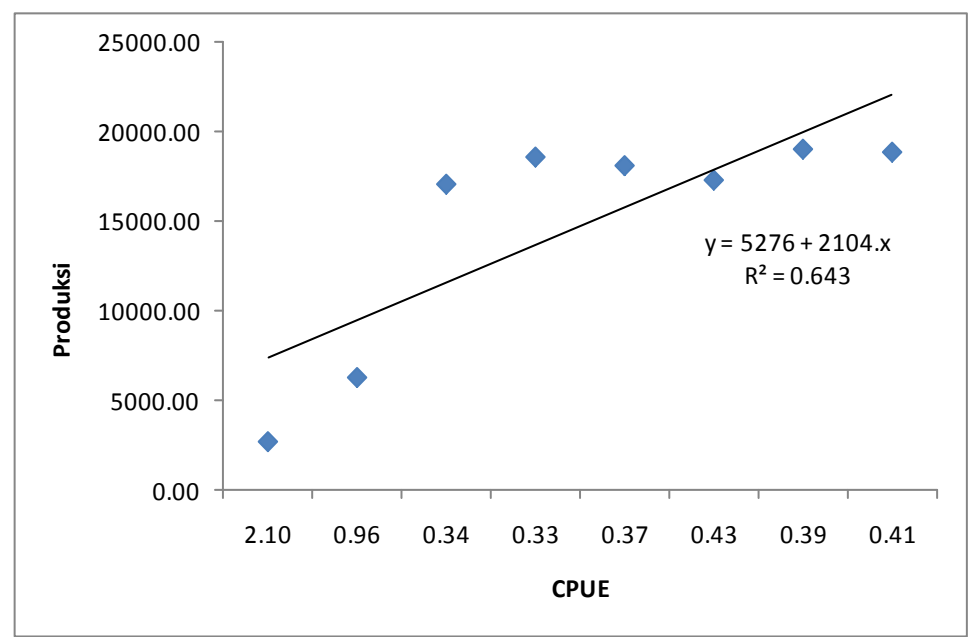

Gambar 2 Hubungan antara Produksi dengan CPUE di Kota Ternate

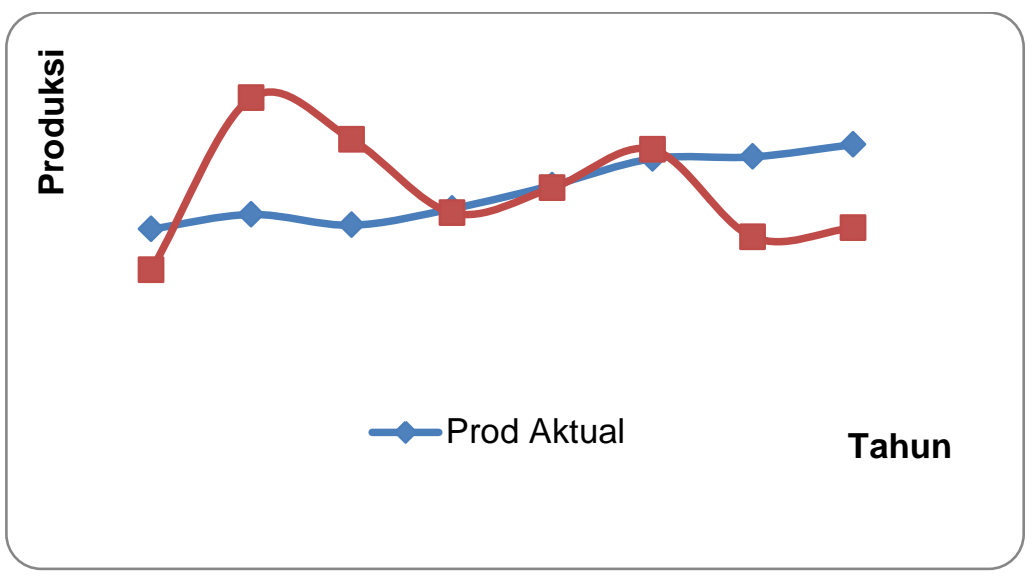

Gambar 3 Hubungan antara produksi actual dan produksi lestari perikanan di Kota Ternate

Gambar 3 terlihat bahwa penambahan upaya (effort) tidak selalu identik dengan peningkatan produksi seperti yang terjadi pada tahun 2006 dan 2007 di mana dengan effort yang tinggi diperoleh hasil tangkapan yang jauh lebih rendah dibandingkan dengan tahun sebelumnya.

Dengan menggunakan persamaan ini dapat diduga produksi lestari dengan metode Schaefer di Kota Ternate setiap tahunnya. Produksi lestari, produksi aktual dan effort aktual yang digunakan dapat dilihat pada Tabel 4.

\subsection{Strategi Pengelolaan Perikanan Tangkap Di Kota Ternate}

Berbagai tahapan dan analisis untuk menentukan status keberlanjutan perikanan pelagis kecil di lokasi penelitian telah dilakukan, di antaranya: (1) analisis sumberdaya (Schaefer, 1954) dan analisis bioekonomi Gordon Schaefer. 
Tabel 4 Effort, produksi aktual dan produksi lestari perikanan pelagis kecil di Kota Ternate

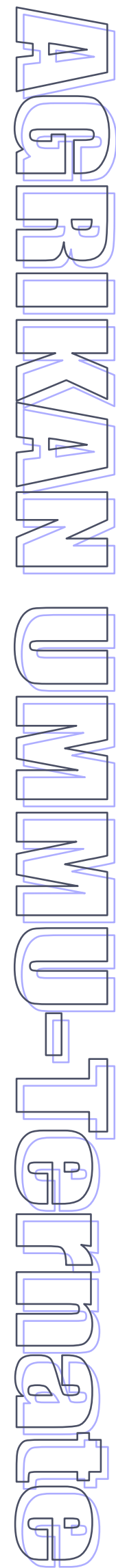

\begin{tabular}{cccc}
\hline Tahun & $\begin{array}{c}\text { Effor } \\
\text { (trip) }\end{array}$ & $\begin{array}{c}\text { Produksi aktual } \\
\text { (ton) }\end{array}$ & $\begin{array}{c}\text { Produksi lestari Schaefer } \\
\text { (ton) }\end{array}$ \\
\hline 2005 & 2723.94 & 5717.4 & 4717.09 \\
2006 & 6298.32 & 6073.7 & 8916.84 \\
2007 & 17070.49 & 5811.5 & 7899.08 \\
2008 & 18582.56 & 6213.7 & 6112.91 \\
2009 & 18104.28 & 6784.1 & 6721.63 \\
2010 & 17297.42 & 7434.5 & 7656.81 \\
2011 & 19021.57 & 7477.3 & 5518.55 \\
2012 & 18855.87 & 7778.3 & 5746.89 \\
\hline
\end{tabular}

Sumber : Hasil olahan

Model produksi surplus, dalam pendugaan potensi lestari dilakukan untuk melihat kondisi sumberdaya secara akurat dan obyektif sesuai dengan tujuan penelitian. Dengan metode diatas dapat dilihat kondisi riil di lapangan agar prinsip kehati-hatian betulbetul menjadi prinsip dasar dalam pengelolaan sumberdaya perikanan pelagis kecil.

Perhitungan parameter biologi, maupun tekhnis terhadap data yang ada menghasilkan nilai-nilai yang diperlukan untuk analisa selanjutnya. Dari data diatas menunjukkan hasil tangkapan maksimum lestari (MSY) pelagis kecil di Kota Ternate menurut Schaefer dimana telah terjadi overfishing. Hal ini menunjukkan bahwa pada wilayah kota Ternate (laut Maluku) sudah terjadi fully exploited. Hal ini dikarenakan daerah tangkapan nelayan masih pada wilayah yang sempit dengan armada yang banyak dan effort yang lebih besar. Ada beberapa alasan terjadinya gejala overfishing diantaranya : 1) produktifitas hasil tangkapan menurun, 2) terjadinya booming spesies tertentu, 3) penurunan ukuran ikan hasil tangkapan, 4) grafik penangkapan dalam satuan waktu berbentuk fluktuasi atau tidak menentu (eractic), 5) penurunan produksi secara nyata /significant.

\section{KESIMPULAN DAN SARAN}

\subsection{Kesimpulan}

1. Hasil analisis bioekonomi dengan model Schaefer menunjukkan potensi produksi lestari (maximum Suistainable Yield/MSY) jenis sumberdaya ikan Pelagis khususnya Cakalang sebesar 10.999,65 ton/tahun, dengan upaya penangkapan maksimum 11.150,43 unit alat tangkap Ini menunjukkan perairan kota Ternate (laut Maluku) telah fully exploitacy sehingga perlu adanya pengaturan pengelolaan yang baik sehingga menciptakan keseimbangan yang lestari

2. Hasil perhitungan faktor produksi terhadap alat tangkap pole and line dan purse seine didapatkan adanya hubungan yang nyata antara hasil tangkapan dengan jumlah bahan bakar, umpan hidup dan kapasitas ukuran kapal, serta jumlah tenaga kerja serta banyaknya hari tangkapan. Dengan penambahan faktor-faktor produksi tersebut memberikan produksi hasil tangkapan yang semakin meningkat Namun tidak semua faktor produksi harus berdampak pada peningkatan produksi. Adanya pembatas pada faktor teknik produksi seperti jumlah bahan bakar yang dibawa oleh kapal penangkap dibatasi oleh tanki atau wadah bahan bakar, karena keterbatasan ruang di kapal.

\subsection{Saran}

Aktifitas pemanfaatan yang cukup tinggi di perairan Kota Ternate dikarenakan adanya pembagian wilayah perairan dengan batas administrasi wilayah menyebabkan terjadinya ketidaktentuan aktifitas nelayan dalam menjalankan usaha penangkapannya, baik nelayan dari wilayah administrative Kota/Kabupaten maupun Propinsi. Perlu adanya kebijakan baik dari Pemerintah Kota/Kab maupun Propinsi tentang pembagian wilayah tangkapan berdasarkan jenis alat tangkap serta armada 


\section{DAFTAR PUSTAKA}

Aziz KA, Boer M, Widodo J, Naamin N, Amrullah M H, Bidawi H, Djamali A, Priyono B E. 1998. Potensi Pemanfaatan dan Peluang Pengembangan Sumberdaya Ikan Laut di Perairan Indonesia. Komisi Nasional Pengkajian Sumberdaya Perikanan Laut (KOMNAS KAJISKANLUT), Jakarta.

Badan Pusat Statistik Kota Ternate. 2006 - 2014. Kota Ternate dalam Angka. Perkembangan Produksi Hasil Perikanan di Kota Ternate

Clark C W. 1976. Mathematical Bioeconomic: The Optimal Management of Renewable Resources. Jhon Wiley \& Sons. New York.

Dahuri R. 2001. Estimasi Potensi, Peluang Pengembangan dan Tingkat Pemanfaatan Sumberdaya Ikan Tuna dan Cakalang (Ikan Pelagis) di Indonesia. Seminar Nasional Potensi Kelautan di Indonesia, Jakarta. 10 Hal.

[DPK] Dinas Perikanan dan Kelautan Provinsi Maluku Utara. 2012. Statistik Perikanan Tangkap Provinsi Maluku Utara tahun 2012. Ternate. 62 hal.

FAO. 1991. Interaction of Pasific Tuna Fisheries. Vol 2. Paper on Biology and Fisheries. FAO. Rome. 137 p.

Fauzi A dan Anna S. 2005. Pemodelan Sumber Daya Perikanan dan Kelautan. Jakarta : PT. Gramedia Pustaka Utama. 353 hal.

Fauzi A. 2005. Kebijakan Perikanan dan Kelautan, Isyu, Sintesis dan Gagasan. Gramedia Pustaka Utama. Jakarta.

Fox WW,Jr. 1970. An Exponential Surplus-Yield Model for Optimizing Exploited Fish Population. Transactions of the American Fisheries Society. P 80-88.

Schaefer M. 1957. A Study of the Dynamics of the Fishery for Yellowfin Tuna in the Eastern Tropical pacific. Inter am. Trop. Comm. Bull 2. P 247-268.

Sparre P, SC Venema. 1999. Introduction to tropical fish stock assessment. Training in fish stock assessment and fisheries research planning. GCP/INT/392/den FAO/Danida

Stell R G D and J H Torrie. 1981. Principiles and Procedures Of Statistics. Second Edition. Mc Graw Hill Int. Book Co. 633 p. 